Session 3553

\title{
Creating a Learning Community in a Freshman Design Course with a Senior High-School Class and a Freshman Graphics Class
}

\author{
Greg Mason and Teodora Rutar \\ Seattle University
}

\begin{abstract}
The importance of developing "learning communities" in which students interact with those outside their class has recently been emphasized by several national educational initiatives, including the National Science Foundation. This paper discusses how a learning community is used in an engineering design course to teach students to work on design teams in which team members have diverse educational backgrounds, and are located at different geographic locations. This simulates the design environment that is common in industry.
\end{abstract}

The learning community is formed by coordinating the curricula from three different courses: a college freshman design course, a college freshman graphics course, and a high school technology course. The learning community is established to design a product. Students from each course participate in the design process at different levels. The primary design responsibility is with the freshman design class. The design documentation is provided through the interaction between the high school students and the students in the freshman graphics class. The fabrication responsibility lies on the high school students. The designs are tested and analyzed in the freshman design class. At each step of the design, students from the three separate courses must communicate through email and video conferencing in order to coordinate their separate design efforts.

The primary objectives of the learning community are to: 1) develop communication skills necessary for meaningful technical interaction between colleagues with diverse educational backgrounds; 2) develop students' awareness that material taught in one course is related and applied in other courses; and 3) develop communication and research skills within the design process early in students' careers.

This paper presents detailed curricular objectives, describes how the curricula from the separate courses were coordinated, and provides results obtained by assessing student learning. 


\section{Introduction}

Collaborative learning has long been a goal of design curriculums. Pedagogical studies show that students simply learn more if they are actively involved in the learning process [1,2] and if they interact with other students [3]. Collaboration and interaction are especially important in engineering design. Engineering design requires synthesis - a process that is greatly enhanced when students collaborate with others who have ideas different from their own.

One common characteristic of traditional design courses is that they are taught with design teams comprised of students attending the same class and having similar educational backgrounds. Such courses do not teach students how to work on design teams where members may have significantly different technical backgrounds or may be located at different geographical locations. Collaboration with others from diverse backgrounds and locations is an important part of the learning process and common in real world design practice.

To address the problem of collaborative learning, and involve students in design teams made up of educationally and geographically diverse members, Seattle University and Central Kitsap High School developed a "learning community". The "learning community" brings together students from three different classes from both university and high school to participate in a quarter-long design project. This "learning community" is described herein.

The remainder of this paper is divided into five sections. In section two, the overall goals and objectives of the learning community are presented. Section three provides an overview of the courses participating in the learning community. Section four discusses how the learning community was implemented. Section five presents the assessment results. Conclusions and recommendations are provided in section six.

\section{Learning Community Objectives}

The goal of the learning community is to provide students with design team experience where they must learn to work with members of diverse backgrounds and at different geographic locations. The teams are comprised of members from three different courses (two freshman classes at Seattle University and one class at Central Kitsap High School). The teams are assigned a design project that extends from initial literature review and research phase through brainstorming, prototyping, sketching, evaluating, redesigning, and building, to final testing, documenting, and reporting. The team members from each course contribute to the product design with different skill sets. The student roles are predetermined and do not overlap between classes, mimicking the real world product development setting. Communication between the university and the high school team members is done using only internet and teleconferencing.

In addition to the educational objectives for the individual courses, the learning community has the following specific objectives: 
Objective 1: To teach students to work in diverse groups and to develop the communication skills necessary for meaningful technical interaction between colleagues with diverse educational backgrounds.

Objective 2: To teach students to use technology such as email, video teleconferencing, and the internet to communicate technical ideas with colleagues at different geographical locations.

Objective 3: To provide students with a design experience, which extends beyond the classroom and develops their awareness that material taught in one course is related to, and applied in other courses.

Objective 4: To develop students' communication and research (educated and informed decisionmaking) skills and bestow awareness early in their career that these skills are integral parts of the design process.

Objective 5: To engage high school students in the design process, and encourage them to pursue a career in science or engineering.

\section{Participating Courses}

The courses participating in the learning community are: 1) MEGR181 Innovative Design, 2) MEGR105 Engineering Graphics, and 3) CKHS091 CAD. These three courses are comprised of mechanical, civil, and electrical engineering students from Seattle University and of technology students from Central Kitsap High School.

MEGR181 Innovative Design: MEGR181 is a two quarter-credit freshman design course at Seattle University. The course is the first design class in the curriculum. It provides an introduction to engineering and focuses on the basics of the design process. The course includes a major team design project which requires students to apply major design process steps: identifying functional requirements and constraints, researching, identifying alternatives, evaluating, decision making, building and testing a prototype, redesigning, and building, testing, and reporting the final design. In addition, students are required to write memorandums and reports, and give PowerPoint presentations. MEGR181 is required of all mechanical and electrical engineering students at Seattle University.

MEGR105 Engineering Graphics: MEGR105 is a three quarter-credit freshman course at Seattle University. The course covers the fundamentals of interpreting and producing engineering drawings, the use of solid modeling as a design tool, and the creation of technical illustrations for reports and presentations. The course is designed to give students a working knowledge of dimensioning, tolerancing, orthographic projections, and section views. MEGR105 is required of all mechanical and civil engineering students at Seattle University. 
CKHS091 CAD: CKHS091 is a drafting course taught at Central Kitsap High School. The course is part of a two-year sequence of Computer Aided Drafting (CAD) courses available at the high school. This course is taken in the second year of the program. The course focuses on drafting practices and industrial standards. Emphasis is placed on two-dimensional orthographic drawings. Students also learn to create sculpted three-dimensional models, which are printed on the school's stereolithography machine.

One key to the success of the learning community is that the three courses have overlapping themes but different focuses. This makes it possible to identify common aspects of the courses for the curriculum coordination.

Another key is that the student population of the three courses is different. Thus, one of the goals of the learning community, to force students to interact with those outside of the course, is accomplished. The only student overlap is mechanical engineering students who enroll in both MEGR105 and MEGR181 in the same quarter. This overlap has actually proven to be beneficial because it allows for teams with at least one member who attends both Seattle University courses. These individuals then serve as coordinators for the project.

A final key is that sixty miles separate the high school and the university. This means face-toface student contact is limited. This forces students to rely on email and video teleconferencing as a means of communication (this is one of our goals). Students quickly learn that they must be concise and accurate when they communicate with other members of their team in order to avoid miscommunications that delay their project.

\section{Implementing the Learning Community}

The learning community centers around a common design project. Teams of students are responsible for the design, analysis, documentation and fabrication of their ideas. To encourage team competitions, the project concludes with a final test where teams compare the performance of their designs.

The assigned project is to design and build a turbine blade for a wind-powered generator. The completed turbine blades are then mounted to the shaft of a small electrical generator. The only design restrictions are that the blades must have a rotational diameter of less than 8 inches, and the hub of the turbine must fit a pre-specified shaft. These requirements ensure that the turbine will fit inside the wind tunnel used for testing, and that they will properly mate to the generator shaft. Final testing of the turbines is performed inside a portable wind tunnel (maximum wind speeds are $5 \mathrm{~m} / \mathrm{s}$ ). The wind tunnel is shown in Figure 1.

The design task is assigned to teams made up of students from each of the three courses discussed in the previous section. Thus, each design team has electrical and mechanical engineering students from MEGR181, civil and mechanical engineering students from MEGR105 and high school students from CKHS091. Students from each course are given 
different responsibilities on the team. These responsibilities parallel the course work for their specific class. MEGR181 students are responsible for the research, conceptual design, final testing, and reporting. MEGR105 students oversee the engineering documentation. CKHS091 students create the dimensioned orthographic drawings and fabricate the turbine blades. While the students each have their own responsibility, they still must work together and communicate effectively in order for the project to be a success.

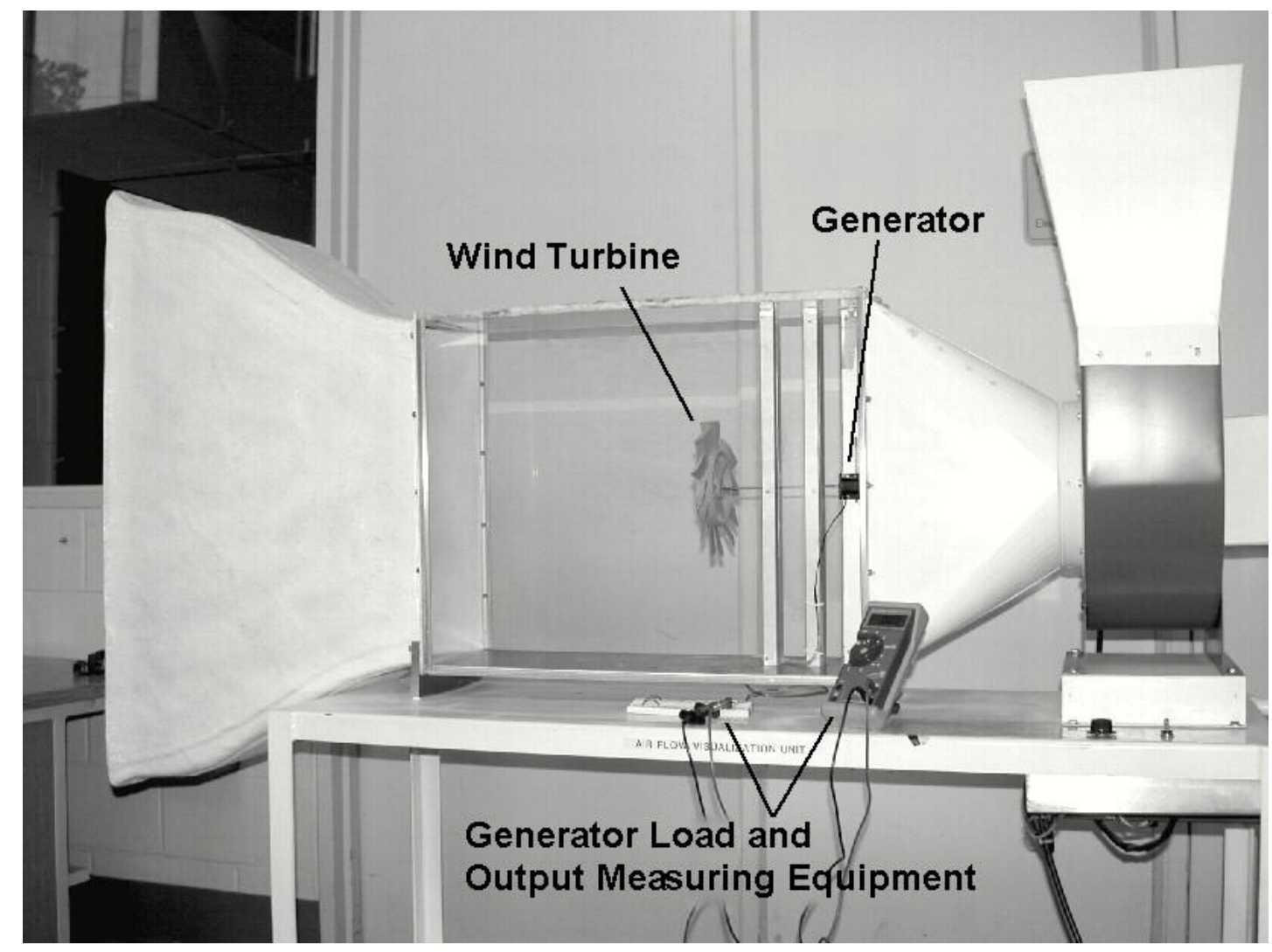

Figure 1. Portable wind tunnel used for turbine testing.

A flow chart of the project is shown in Figure 2. The project begins with the initial research and conceptual design performed by the MEGR 181 students. The conceptual designs are emailed to the students at Central Kitsap High School in the form of conceptual sketches and accompanying memorandums. This is followed by team meetings held using video teleconferencing. During the conferences, teams discuss the design concept and answer questions from the high school students. Next, the high school students produce preliminary drawings of the part. These drawings are emailed to the MEGR105 students at Seattle University where they are reviewed for accuracy. Since at least one of the MEGR105 students is also enrolled in MEGR181, the drawings are also reviewed to ensure that they match the original design concepts. The drawing review is followed by email and video teleconferencing until the design and drawings are finalized. Central Kitsap High School students then use the dimensioned drawings to produce 
physical prototypes using a stereolithography machine. The prototypes are shipped to Seattle University for testing in MEGR181 and redesigned as needed. Design changes are communicated back to the high school team members via email and video teleconferencing. The high school students produce the final drawings and fabricate the final design with the stereolithography machine. The final drawings are sent to the MEGR105 for creation of technical illustrations. During the final week of the term, students from all three classes meet at Seattle University for final presentations and testing.

Examples from a typical project are shown in Figures 3 and 4. The original conceptual sketches generated by MEGR181 students are shown in Figure 3. These sketches were scanned and emailed to students at Central Kitsap High School. Figure 4 shows the final wind turbine as produced by the stereolithography machine.

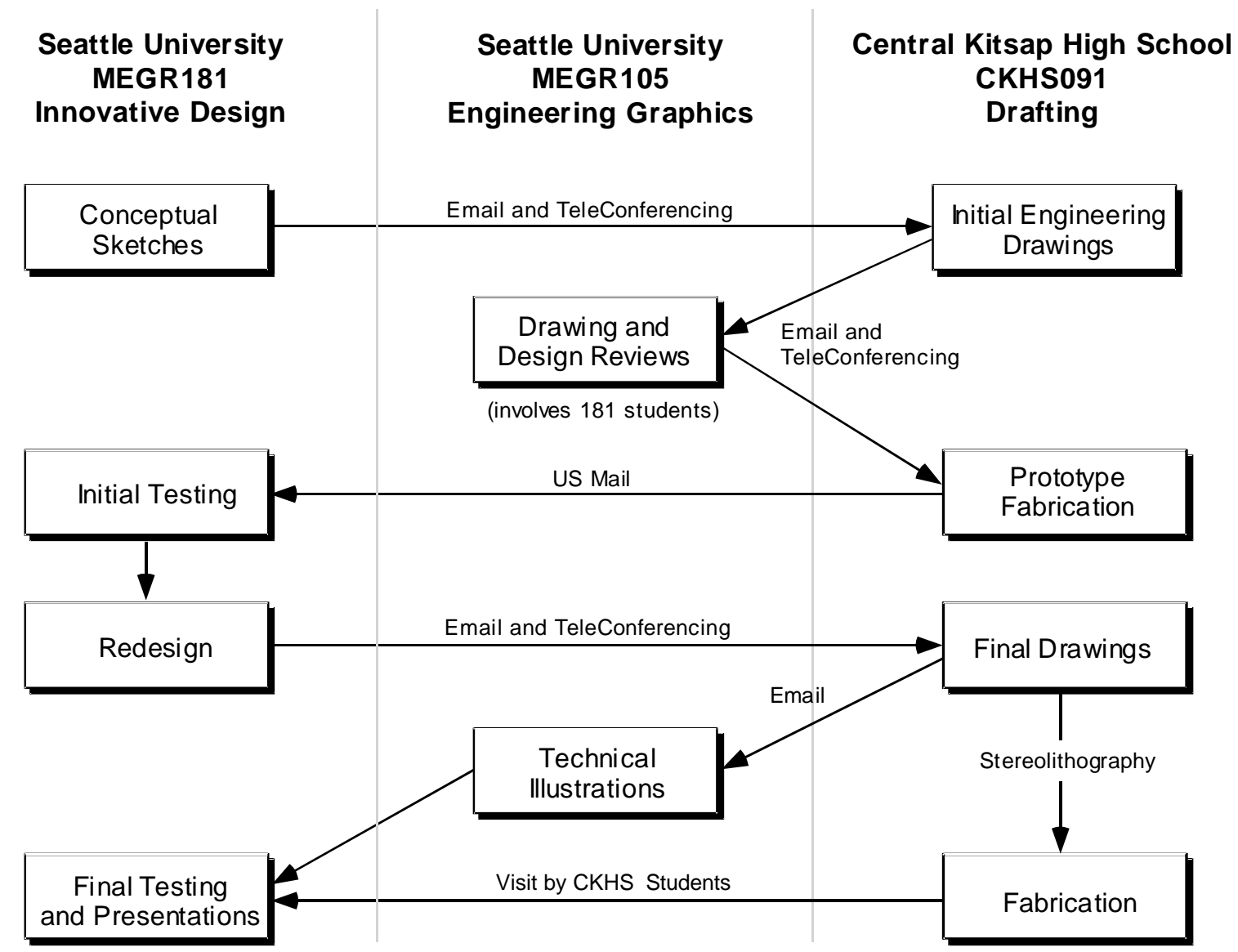

Figure 2. Project Flow Chart 


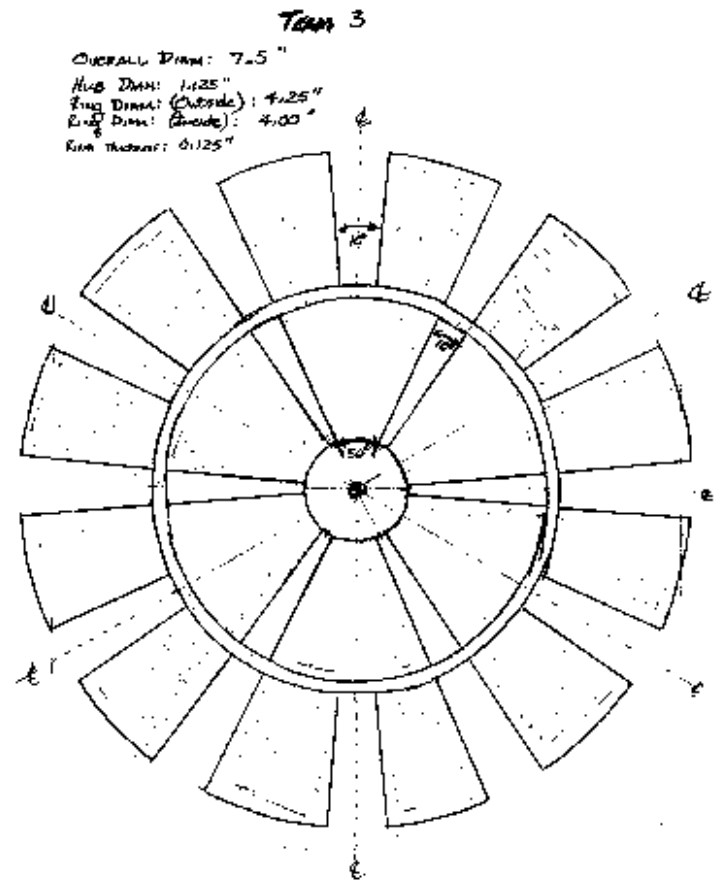

Figure 1
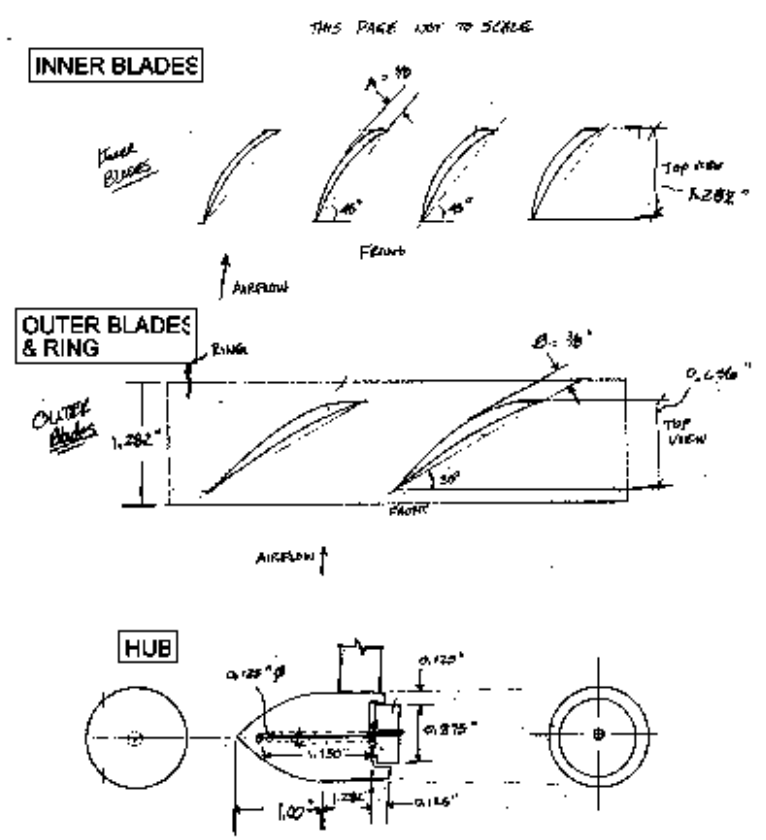

Figure 2

Figure 3. Example of a conceptual design sketch provided to the high school team members by students in MEGR 181.
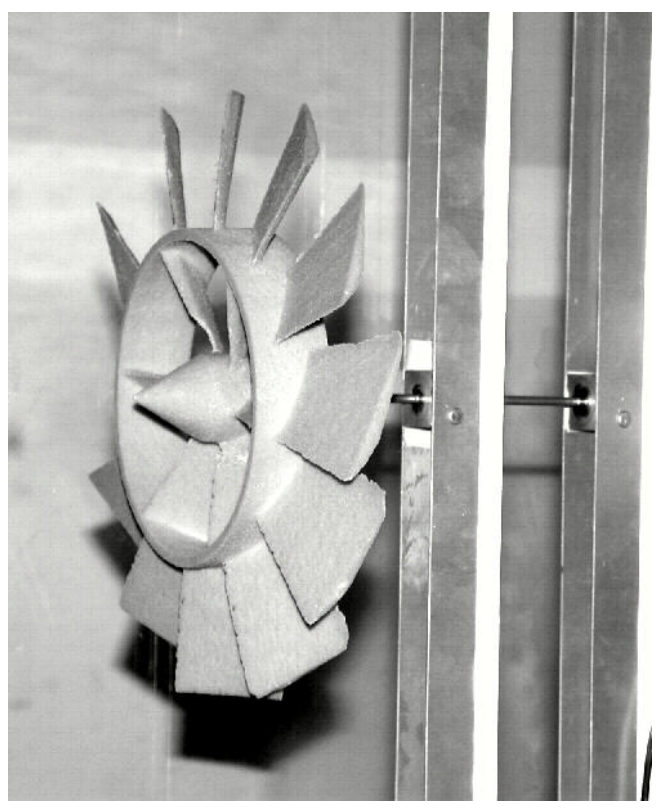

Figure 4. Final wind turbine produced by the stereolithography machine.

Proceedings of the 2002 American Society of Engineering Education Annual Conference \& Exposition Copyright (C) 2002, American Society for Engineering Education 


\section{Assessment Results}

The learning community was implemented for the first time during the Fall Quarter of 2001. The initial success of the program was evaluated through two assessment measures: 1) surveys of the participating faculty and 2) surveys of the students.

Faculty surveys were performed informally, since only three instructors participated in the learning community. The consensus was that the learning community did indeed provide an excellent forum for student interaction. The faculty observed that the students tended to change their communication style as the term progressed. This happened as they learned, firsthand, the pitfalls of poorly communicating their ideas to other students on their design team. At the end of the term, several students commented on the importance of communication in the project and what could be done to improve the course the following offering. The high school instructor also noted that there was a marked interest in the "hard" sciences from his students. This was very positive, since one of the goals of the learning community was to encourage high school students to pursue science and engineering careers.

The student surveys utilized a short-term assessment process. This process consists of three surveys, taken at the third, sixth and ninth weeks of the quarter. The second survey is followed up by a class visit from an outside instructor. Details of the short-term assessment process are outlined in [4]. As a baseline for comparison, identical surveys were given to two separate sections of MEGR181. One of these sections participated in the learning community, while the other section did not participate in the learning community. The curricula for the two MEGR181 sections were identical, except for the learning community component. The results of the student surveys for selected questions are shown in Table 1. The student surveys showed a marked difference in the perceived learning between the class that participated in the learning community, and the class that did not. Most notable were the differences on questions relating to teamwork and on questions about the project itself. The higher ratings in the teamwork question for the "learning community class" can be attributed to the fact that students who participated in the learning community were required to spend significantly more time on the "team" aspects of the projects. They were required to compose emails to send to other members of their team and had to prepare for, and participate in, several video teleconferencing sessions. It's also interesting to note that the students in the learning community felt that they had a better grasp on why and how a wind turbine is used for power generation. This is no doubt because the MEGR181 students in the learning community were required to explain the project to their counterparts at Central Kitsap High School. The rest of the ratings are quite similar between the two sections, with exception of the first one. The "learning community" class showed consistently higher interest than the other class. 
Table 1. Survey Results for Selected Questions

\begin{tabular}{|c|c|c|c|c|c|c|c|c|}
\hline \multirow[b]{2}{*}{ Survey \# } & \multicolumn{4}{|c|}{$\begin{array}{c}\text { With } \\
\text { Learning Community }\end{array}$} & \multicolumn{4}{|c|}{$\begin{array}{c}\text { Without } \\
\text { Learning Community }\end{array}$} \\
\hline & 1 & 2 & 3 & Avg & 1 & 2 & 3 & Avg \\
\hline $\begin{array}{l}\text { Rate your interest in taking ME181 } \\
\text { now. }\end{array}$ & 4.2 & 4.0 & 3.6 & 3.9 & 3.4 & 3.6 & 3.4 & 3.5 \\
\hline $\begin{array}{l}\text { Rate the importance of technical } \\
\text { writing in engineering. }\end{array}$ & 4.4 & 4.2 & 4.4 & 4.3 & 4.1 & 4.3 & 4.3 & 4.2 \\
\hline Rate your technical writing skills. & 3.1 & 3.2 & 3.8 & 3.4 & 2.9 & 3.4 & 3.7 & 3.3 \\
\hline $\begin{array}{l}\text { Rate the importance of teamwork in } \\
\text { engineering practice. }\end{array}$ & 4.9 & 4.8 & 4.8 & 4.8 & 4.6 & 4.7 & 4.7 & 4.6 \\
\hline Do you enjoy working in a team? & 4.4 & 4.4 & 4.4 & 4.4 & 3.6 & 4.5 & 3.7 & 3.9 \\
\hline $\begin{array}{l}\text { Could you explain design constraints } \\
\text { and functional requirements? }\end{array}$ & 3.9 & & & 3.9 & 4.1 & & & 4.1 \\
\hline $\begin{array}{l}\text { Could you name main steps in the } \\
\text { design process? }\end{array}$ & 3.7 & & & 3.7 & 3.6 & & & 3.6 \\
\hline $\begin{array}{l}\text { Could you explain advantages and } \\
\text { disadvantages of using wind turbines } \\
\text { for electricity generation? }\end{array}$ & & & 4.2 & 4.2 & & & 3.5 & 3.5 \\
\hline
\end{tabular}

Additional student comments can be summarized as following:

1. Increasing the frequency of the meetings would speed up the design process. This can be achieved with more frequent use of email or through the use of web-cams. Web-cams would also reduce the embarrassment effect of communicating while surrounded by a set of teachers, and many other students.

2. High school students should be encouraged to point out all flaws in the MEGR181 sketches, and ask for clarification on all ambiguities. The high school students must make sure that they have complete understanding of the drawings.

3. Make students accountable for communication. For example, all must participate either in organization of meetings or in direct meetings, and take responsibility for communication effectiveness. 


\section{Conclusions and Recommendations}

There are several changes that need to be implemented for the next term.

First, students and faculty alike struggled with the logistics of email-based meeting and video teleconferencing. On several occasions meetings had to be cut short or canceled simply because of technological problems. These technological issues need to be resolved for the following term.

Second, design teams were required to share a single video teleconferencing facility. This limited the amount of time teams could meet together. In general, students wanted to meet more often than was practical. Next term the internet will be used for video conferencing. This will allow students to arrange their own meetings. It also means that multiple teams can meet simultaneously instead of having to share the video conferencing facility.

Third, participation of the MEGR105 class was less than initially planned. Delays in getting the projects started meant students were rushed for time and didn't have adequate time for proper drawing and design reviews. In the future, projects will be started earlier to allow time for design reviews.

Finally, students relied on the stereolithography machine for fabrication. The particular machine creates "plaster" parts impregnated with wax. Many of the designs proved too fragile when fabricated with this "plaster" material. Several alternative materials and coatings to strengthen the parts are being investigated for the next term.

Bibliography:

[1] Finelli, C. J., Klinger A., and Budny, D. D., "Strategies for Improving the Classroom Environment." ASEE Journal of Engineering Education, Vol. 90, No. 4, October 2001.

[2] Association of Experiential Education (1999), accessed on January 14, 2002, http://www.aee.org/

[3] Terenzini, P.T., Cabrera, A.F., Colbeck, C.L., Parente, J.M., and Bjorklund, S.A., "Collaborative Learning vs. Lecture/Discussion: Students’ Reported Learning Gains.” ASEE Journal of Engineering Education, Vol. 90, No. 1, January 2001.

[4] Rutar, T. and Mason, G., "Short-Term Course Assessment, Improvement, and Verification Feedback Loop."

Proceedings of the 2001 American Society of Engineering Education Annual Conference \& Exposition, 2001

\section{GREG MASON}

Greg Mason is Assistant Professor at Seattle University, Department of Mechanical and Manufacturing Engineering. He received a B.S. in Mechanical Engineering from Gonzaga University, an M.S. in Computer Integrated Manufacturing from Georgia Institute of Technology, and the Ph.D. in Mechanical Engineering from the University of Washington. He joined Seattle University in 1993 and has developed the Manufacturing Engineering program. 
TEODORA RUTAR

Teodora Rutar is Assistant Professor at Seattle University, Department of Mechanical and Manufacturing

Engineering. She received a B.S. in Mechanical Engineering from University of Belgrade, Yugoslavia, and an M.S. and a Ph.D. in Mechanical Engineering from the University of Washington. She joined Seattle University in Spring Quarter 2000, upon completion of her Ph.D. She pursues research in environmentally conscious combustion. 